ARTICLE

\title{
Rewetting does not return drained fen peatlands to their old selves
}

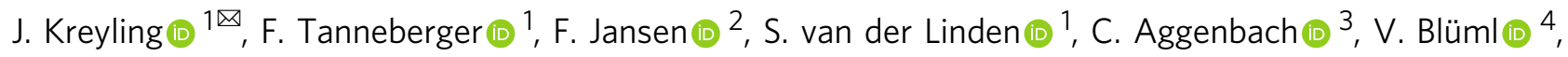

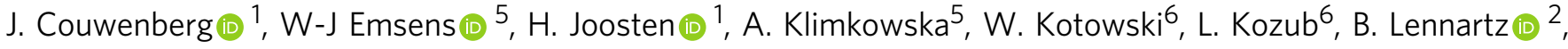

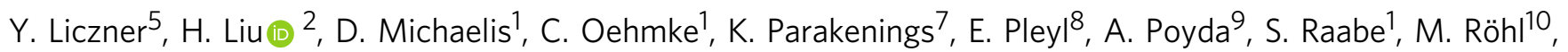
K. Rücker ${ }^{9}$, A. Schneider ${ }^{11}$, J. Schrautzer ${ }^{9}$, C. Schröder ${ }^{12}$, F. Schug ${ }^{13}$, E. Seeber ${ }^{1}$, F. Thiel $^{1}$, S. Thiele ${ }^{14}$, B. Tiemeyer ${ }^{15}$, T. Timmermann ${ }^{1}$, T. Urich (1) ${ }^{1}$, R. van Diggelen (D) ${ }^{5}, K_{\text {. Vegelin }}{ }^{16}$, E. Verbruggen (D) ${ }^{5}$, M. Wilmking (i) ${ }^{1}$, N. Wrage-Mönnig (1) ${ }^{17}$, L. Wołejko ${ }^{2}$, D. Zak (i) ${ }^{18,19}$ \& G. Jurasinski (i) ${ }^{2}$

Peatlands have been drained for land use for a long time and on a large scale, turning them from carbon and nutrient sinks into respective sources, diminishing water regulation capacity, causing surface height loss and destroying biodiversity. Over the last decades, drained peatlands have been rewetted for biodiversity restoration and, as it strongly decreases greenhouse gas emissions, also for climate protection. We quantify restoration success by comparing 320 rewetted fen peatland sites to 243 near-natural peatland sites of similar origin across temperate Europe, all set into perspective by $10 \mathrm{k}$ additional European fen vegetation plots. Results imply that rewetting of drained fen peatlands induces the establishment of tall, graminoid wetland plants (helophytisation) and long-lasting differences to pre-drainage biodiversity (vegetation), ecosystem functioning (geochemistry, hydrology), and land cover characteristics (spectral temporal metrics). The Paris Agreement entails the rewetting of $500,000 \mathrm{~km}^{2}$ of drained peatlands worldwide until 2050-2070. A better understanding of the resulting locally novel ecosystems is required to improve planning and implementation of peatland rewetting and subsequent management.

\footnotetext{
${ }^{1}$ University of Greifswald, partner in the Greifswald Mire Centre, Greifswald, Germany. ${ }^{2}$ University of Rostock, Rostock, Germany. ${ }^{3}$ KWR Water Research Institute, Nieuwegein, The Netherlands. ${ }^{4}$ BMS-Umweltplanung in association with University of Bremen, Osnabrück, Germany. ${ }^{5}$ University of Antwerp, Antwerp, Belgium. ${ }^{6}$ University of Warsaw, Faculty of Biology, Warsaw, Poland. ${ }^{7}$ Landkreis Vorpommern-Greifswald, Anklam, Germany. ${ }^{8}$ Zentrum für Umwelt und Kultur Benediktbeuern e.V., Benediktbeuern, Germany. ${ }^{9}$ Christian-Albrechts-Universität Kiel, Kiel, Germany. ${ }^{10}$ Hochschule für Wirtschaft und Umwelt Nürtingen-Geislingen, Nürtingen-Geislingen, Germany. ${ }^{11}$ Regional administration Havelland, Nauen, Germany. ${ }^{12}$ Stiftung Umwelt und Naturschutz M-V, Bugewitz, Germany. ${ }^{13}$ Humboldt-Universität zu Berlin, Berlin, Germany. ${ }^{14}$ Institut für Landschaftsökologie und Naturschutz GmbH,

Greifswald, Germany. ${ }^{15}$ Thünen-Institute of Climate-Smart Agriculture, Braunschweig, Germany. ${ }^{16}$ BNL Vegelin; Groß Polzin, Greifswald, Germany. ${ }^{17}$ West Pomeranian University of Technology Szczecin, Szczecin, Poland. ${ }^{18}$ Leibniz-Institute of Freshwater Ecology and Inland Fisheries, Berlin, Germany. ${ }^{19}$ Aarhus

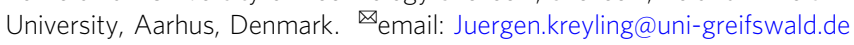


lready in 1658, the world's first scientific book on peatlands ${ }^{1}$ included a chapter on peatland restoration and addressed the question of their long-term use. However, centuries of peatland destruction followed and large-scale restoration of drained peatlands is just about to begin ${ }^{2}$. Despite some progress in understanding ecological functioning of rewetted peatlands $s^{3-5}$, the early warning from 1764 that restoration success may be slow 6 can only now be quantified at a substantial amount of rewetted sites, across continental scales and multiple ecosystem functions.

Intact peatlands provide numerous ecosystem services. They store huge amounts of carbon $\left(600 \pm 100 \mathrm{Gt}^{7}\right.$; thus $30 \%$ of the global soil carbon is found on only $3 \%$ of the global land ${ }^{5,8}$ ), they regulate water quality and quantity, and they harbor highly specialized biota $^{9-12}$. Approx. $500,000 \mathrm{~km}^{2}$, i.e., $10-15 \%$ of the current peatland area, have been drained for agriculture, peat extraction and forestry, historically mainly in temperate and boreal regions, but more recently also in the tropics ${ }^{13}$. Drainage of peatlands impairs their ecosystem service provisioning. Peat oxidation in drained peatlands is responsible for about $5 \%$ of the global anthropogenic greenhouse gas (GHG) emissions ${ }^{12,14}$. Peat mineralization leads to ongoing land subsidence ${ }^{15}$ and turns drained peatlands into sources of nutrients, causing eutrophication of downstream surface and groundwater ${ }^{16}$. A fundamental distinction is commonly made between bogs that are solely fed by rainwater, and fens that also receive ground- and/or surface water that has been in contact with the mineral soil or bedrock ${ }^{10}$. Fens cover more than half of Europe's peatland area ${ }^{10}$. Especially temperate fens, which often become nutrient-rich and productive upon drainage, have been drained for agriculture ${ }^{10}$. Consequently, many temperate fen peatland species are globally endangered because of habitat loss $5,17,18$.

Rewetting drained peatlands can strongly reduce or stop net carbon loss immediately ${ }^{14}$ and may lead to new carbon sequestration ${ }^{19,20}$. In contrast, continued emissions from drained peatlands may comprise $12-41 \%$ of the GHG emission budget until 2100 for keeping global warming below +1.5 to $+2{ }^{\circ} \mathrm{C}^{21}$. Compliance with the Paris Agreement implies carbon neutrality by $2050-2070^{22}$ meaning that until then the $500,000 \mathrm{~km}^{2}$ of drained peatlands need to be rewetted, i.e., on average over one million hectares per year. The 2021-2030 UN Decade of Ecosystem Restoration has to meet this challenge.

However, rewetting might not restore natural conditions promptly or even within decades, in particular in severely disturbed and long-drained temperate fens (i.e., groundwater-fed peatlands), where oxidation during drainage has altered peat physical parameters and has led to, for instance, increased bulk density and decreased porosity, hydraulic conductivity and storativity $^{23}$, leading to stronger water table fluctuations. Periodic or episodic inundation can provoke peaks of methane emissions $^{24,25}$. Furthermore, nutrient availability after rewetting is considerably higher than in natural peatlands, mainly because of peat mineralization and fertilization while the peatland was drained $^{4,26}$, and because of mobilization of phosphorus upon rewetting ${ }^{27}$. Consequently, microbial ${ }^{4}$ and plant $^{3}$ communities show prompt recovery towards their pre-drainage status only in previously weakly disturbed ecosystems.

Here, we compare 320 rewetted fen sites with 243 near-natural sites of similar origin from the major fen peatland regions of Europe (Fig. 1), which are further set into perspective by additional $10 \mathrm{k}$ vegetation plots, randomly chosen from $>90 \mathrm{k}$ plots of European fen vegetation ${ }^{18,28}$ to quantify restoration success in terms of biodiversity (vegetation), ecosystem functioning (hydrology, geochemistry), and land cover characteristics. Our data imply that rewetting drained fens induces the establishment of tall, graminoid wetland plants, i.e., a helophytisation, with no trend back to their former biodiversity and ecosystem functioning for at least several decades in more than half of the sites. A better understanding of biodiversity and ecological functions of these locally novel ecosystems is urgently required to assess restoration success and to improve planning and implementation of peatland rewetting and the subsequent management.

\section{Results and discussion}

Rewetted peatlands differ in their biodiversity and ecosystem functioning from near-natural peatlands. Rewetted fen peatlands differ in biodiversity and ecosystem functioning from nearnatural peatlands, in particular regarding plant community composition and geochemistry (Fig. 2a, c). Smaller, but still highly significant differences were detected in hydrology and in land cover characteristics (Fig. 2b, d). The vegetation of the rewetted sites was furthermore less diverse at the plot scale across the range of Hill's diversity numbers (Supplementary Fig. 1; Shannon diversity: $1.46 \pm 0.04$ (mean \pm SE) in rewetted sites; $1.75 \pm 0.04$ in near-natural sites; $\left.p_{\text {t.test }}<0.001\right)$.

The differences in plant community composition between rewetted and near-natural sites are frequently linked to a helophytisation, i.e., the shift to a dominance of tall, graminoid wetland plants, as indicated by significant preferences of tall helophytes such as Typha latifolia or Phalaris arundinacea for the rewetted sites (see Indicator Species Analysis in Supplementary Data 2), by a higher prevalence of the EUNIS 2020 habitat type ${ }^{28}$ "tall helophyte bed" (relative frequency in rewetted peatlands: $25.5 \%$ versus $6.2 \%$ in near-natural peatlands; $\mathrm{Chi}^{2}: p<0.001$; Supplementary Table 1), and by a $66 \%$ higher cover sum of tall helophyte species in rewetted as compared to near-natural sites (Fig. 3i). This helophytisation has implications beyond biodiversity as plant species composition affects carbon cycling by litter quality (e.g., polyphenol content ${ }^{29}$ ), root exudates, and production and consumption of carbon in the rhizosphere, both of which impact gaseous emissions. The tall helophytes are highly conductive for gases due to their aerenchyma, which may increase $\mathrm{s}^{30}$ or suppress ${ }^{31}$ methane emissions. Brown mosses with high peat formation potential ${ }^{32}$ are largely absent from rewetted peatlands dominated by helophytes (Fig. 3j and Supplementary Data 2). While rewetting clearly reduces carbon emissions by inhibiting peat mineralization ${ }^{14,33}$, comparative analyses between the resulting vastly contrasting vegetation types are required to assess the total greenhouse gas effects of rewetting.

The helophytisation after rewetting is presumably caused by altered water table dynamics and geochemistry of rewetted peatlands. Peat mineralization, consolidation and compaction during the drained phase cause subsidence, leading to inundation after rewetting (mean median water table being $5.0 \mathrm{~cm}$ above surface in rewetted sites versus $1.5 \mathrm{~cm}$ below surface in nearnatural sites and maximum water table differing by $74 \%$; Fig. $3 a$, c). Peat mineralization is reflected in the lower organic matter content of the top soil layer $(-18 \%)$ and in the higher bulk density ( $+61 \%$; Fig. $3 f$, e), both of which decrease porosity and hydraulic conductivity ${ }^{23}$, provoking larger water table amplitudes $(+15 \%)$ in rewetted sites (Fig. $3 \mathrm{~b})$. To sum up, inundation and eutrophic conditions promote tall helophytes, and these suppress low vascular plants and mosses by light competition ${ }^{34}$.

Land cover characteristics, i.e., the 208 metrics of the spectraltemporal variability of land surfaces in Earth observation time series $^{35}$, also show differences between rewetted and near-natural peatlands (Fig. 2d), mainly attributed to high variety in the modified normalized difference water index (MNDWI) and the near infrared reflectance $(n I R)$ for rewetted surfaces (Supplementary Table 2). High MNDWI values relate to a high share of open water in the pixels, $n I R$ values correspond to vegetation 


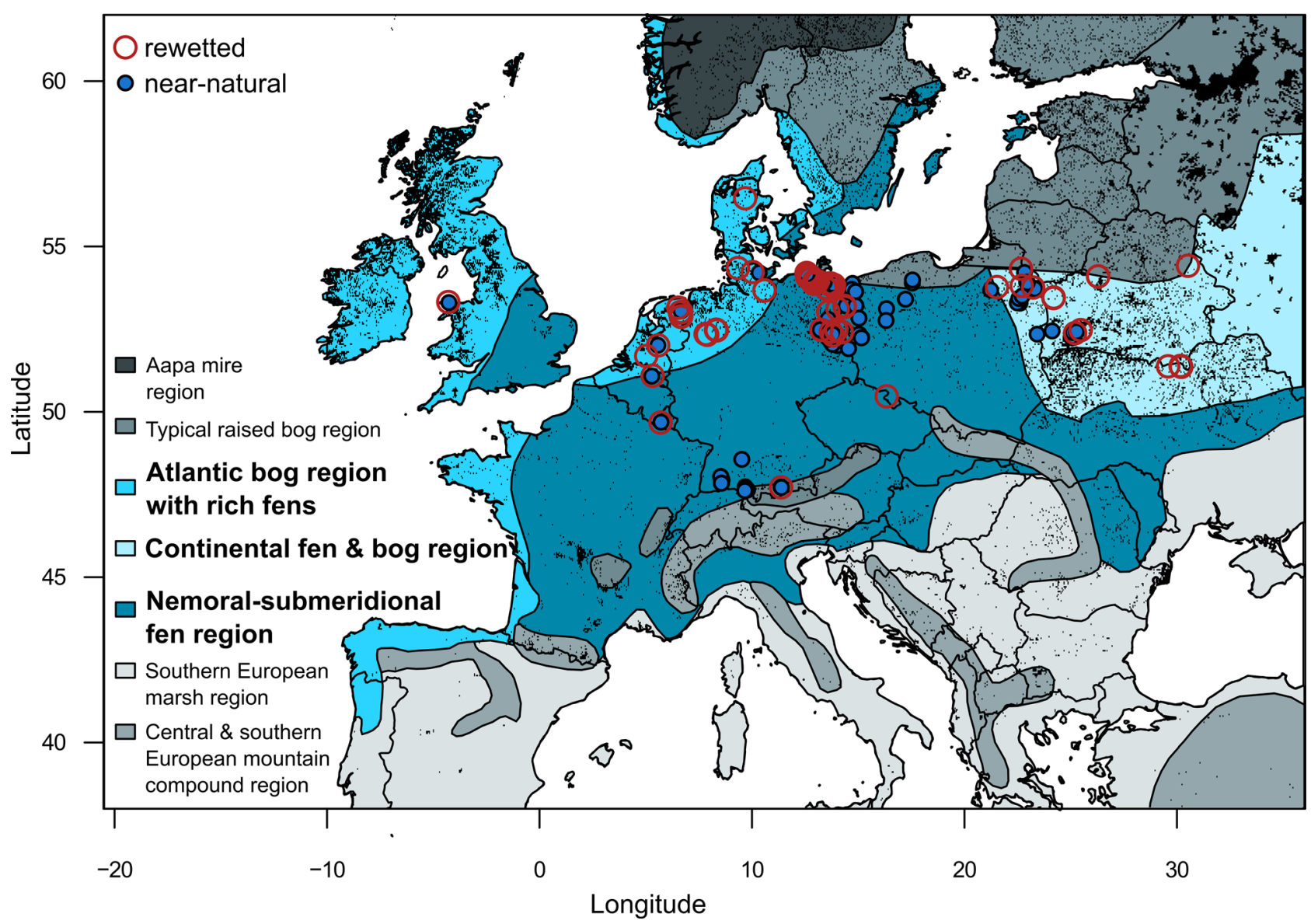

Fig. 1 Map of the study sites contrasting rewetted sites (open red symbols) and near-natural sites (filled blue). We studied temperate fen peatlands, which occur mainly in the mire regions according to Joosten et al. ${ }^{10}$ depicted in shades of blue and set off in bold in the legend. Peatland occurrence according to the Peatland Map of Europe ${ }^{53}$ is shown in black.

density, vigor or type and are lowest for open water. Thus, both metrics relate to differences of the water regime for the vegetated surfaces. The dissimilarity between land cover characteristics in rewetted sites and near-natural sites hints at different pathways after rewetting. Environmental conditions such as hydrology, (chance) priority effects of colonizing species ${ }^{36}$ or former management - the rewetted sites did not differ from nearnatural sites in share of unused sites after rewetting (Fig. 31) - may determine the outcome.

A basic feature of natural peatlands is their stability, which is commonly attributed to a high degree of self-regulation, for instance with regards to buffering hydrological extremes by surface oscillation $^{37}$. Further, stable, azonal species compositions indicate some degree of independence from zonal climate conditions $^{38}$. Plant community composition and carbon dynamics in rewetted peatlands, however, are highly responsive to weather extremes ${ }^{39}$, hinting at a reduced stability. In our dataset, rewetted peatlands in all four response clusters were generally more variant than near-natural peatlands (Fig. 2 insets). This variance of rewetted peatlands may have resulted from a poorly restored hydrology on the landscape level and potentially impairs their ecosystem functioning and service provisioning. For instance, reduced oscillation capacity creates both times with water tables dropping low and inducing carbon dioxide emissions due to increased mineralization ${ }^{40}$, and times of inundation with increased methane emissions ${ }^{24,25}$.

No general trend towards natural conditions up to three decades after rewetting. A strong and, apparently, long-lasting difference in biodiversity, ecosystem functioning, and land cover characteristics between each rewetted site and its closest nearnatural counterpart exists (Fig. 4). Even though $40 \%$ (vegetation) to $80 \%$ (hydrology) of the rewetted sites generally resembled composition or functioning of typical near-natural peatlands (falling into the 95\% confidence ellipses in Fig. 2), the rewetted sites differed strongly from near-natural counterparts in biodiversity (vegetation), ecosystem functioning (hydrology, geochemistry) and land cover characteristics (linear models with $p_{\text {intercept }}<0.001$ for all four response clusters despite low confidence due to small sample size for geochemistry). No detectable trend towards increasing similarity over time (linear models with $p_{\text {slope }}>0.05$ for all four response clusters except vegetation with $p_{\text {slope }}=0.013$ but still a predicted dissimilarity of 0.85 after 5 decades (95\%CI: 0.64 to 1.07); Fig. 4) indicates that restoration success is either reached promptly after rewetting or not at all within the observed three decades covered by our data. Spatial variance exists also between near-natural counterparts of similar origin and distance, but at a much lower level than between rewetted and near-natural counterparts (horizontal dashed lines in Fig. 4 which is not included in the 95\% confidence bands except for geochemistry with its low sample size). In short, time had little to no effect on dissimilarity between rewetted sites and their near-natural counterparts in our data, i.e., time seems to have little to no effect on restoration success for at least three decades.

It is commonly assumed that the stabilization of the water table close to the surface is a premise for successful restoration of peatlands ${ }^{3}$ because too low water tables lead to high carbon 

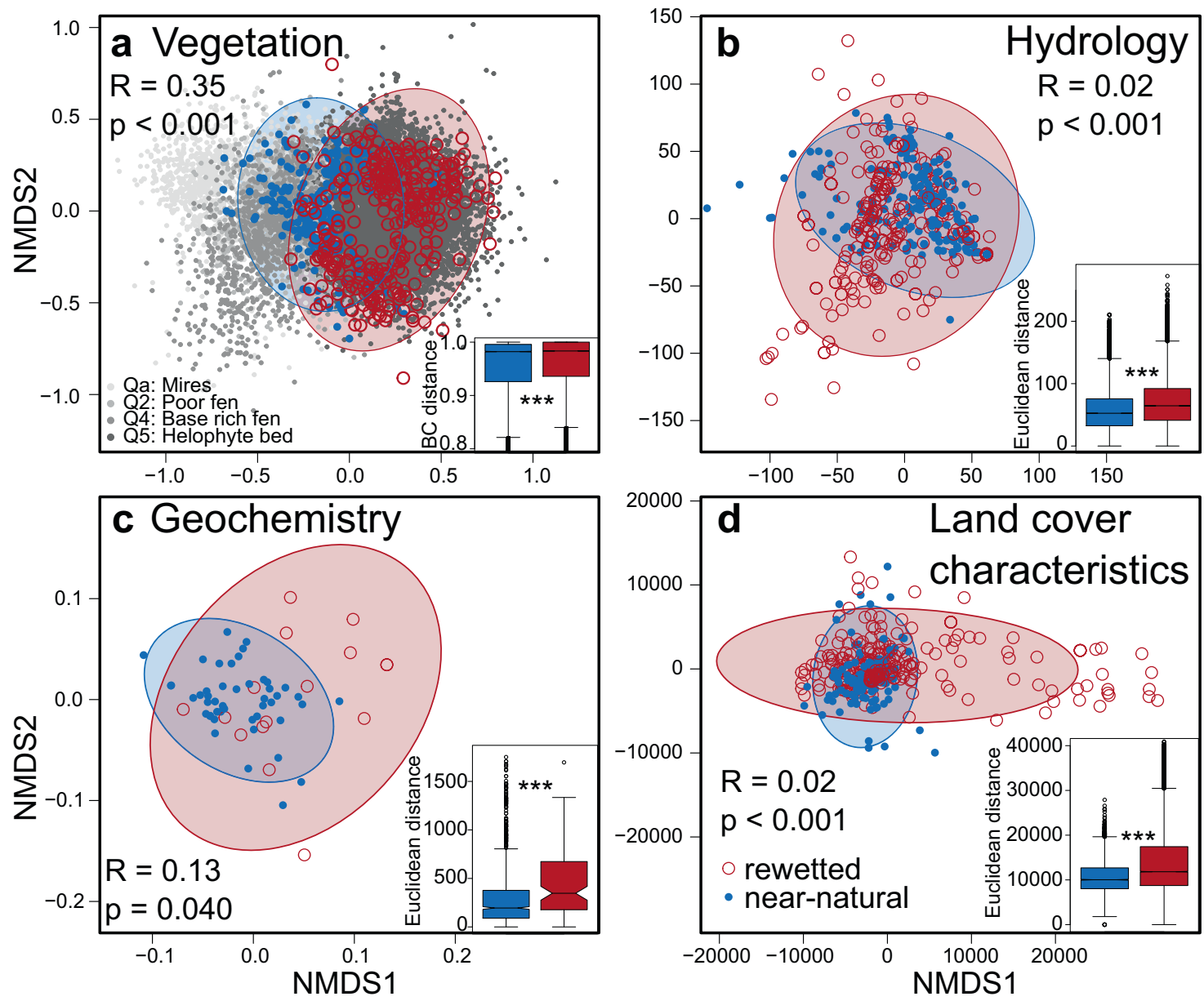

Fig. 2 Rewetted temperate fen peatland sites (open red) are more variable than near-natural sites (filled blue) and many rewetted sites are outside the near-natural range of variation. Ordination (Non-metrical multidimensional scaling; NMDS) and analysis of similarity (ANOSIM) with its respective $R$ value and $p$ value provided in the figures. Dissimilarity is measured as Bray-Curtis distance for (a) vegetation based on 539 plant species $\left(n_{\text {rewetted }}=320, n_{\text {near- }}\right.$ natural $=243$ ), and Euclidean distance for $(\mathbf{b})$ hydrology (based on annual median water table, annual minimum water table, annual maximum water table, annual amplitude of water table; $n_{\text {rewetted }}=320, n_{\text {near-natural }}=243$ ), (c) geochemistry (based on pH of pore water, electrical conductivity of the pore water in the top soil layer, bulk density, organic matter content of the top layer; $n_{\text {rewetted }}=16, n_{\text {near-natural }}=47$ ) and (d) land cover characteristics measured as 208 spectraltemporal metrics of high resolution optical Earth Observation data $\left(n_{\text {rewetted }}=258, n_{\text {near-natural }}=114\right)$. The ellipses display $95 \% \mathrm{Cl}$ for each group. Sample size differs for the four response clusters according to data availability. The vegetation data are set into perspective against 10k vegetation plots randomly selected from $>90 \mathrm{k}$ vegetation plots from Europe of the displayed EUNIS-classes ${ }^{28}$ covering fen vegetation indicating the broad coverage of our near-natural sites. Note that no information about rewetting status is available for these background data. For vegetation, $63 \%$ of the rewetted sites are located outside the $95 \%$ confidence ellipse of the near-natural sites, for geochemistry $44 \%$, for hydrology $20 \%$ and for spectral-temporal metrics $21 \%$, respectively. Final stress of the two-dimensional ordinations are 0.16 for vegetation, 0.02 for hydrology, 0.04 for geochemistry, and 0.12 for land cover characteristics. The inserted boxplots display the median, quartiles (box), 1.5-fold quartile distance (whiskers) and extremes beyond the whiskers of all pairwise distances for rewetted sites in red and near-natural sites in blue ( $\mathbf{a}$ and $\mathbf{b}: n_{\text {rewetted }}=51040, n_{\text {near-natural }}=29403 ; \mathbf{c}: n_{\text {rewetted }}=120, n_{\text {near-natural }}=1081 ; \mathbf{d}: n_{\text {rewetted }}=33,135, n_{\text {near-natural }}=6441$ ).

Significance of difference in mean values between rewetted and near-natural was evaluated by a permutation procedure as described in the methods section $\left({ }^{\star \star \star} p<0.001\right.$ for all four panels).

emissions and non-wetland plants remaining dominant while too high water tables create shallow lakes rather than peatlands. While closest similarity to near-natural counterparts with respect to biodiversity, ecosystem functioning and land cover characteristics indeed occurred for rewetted sites with annual median water tables close to the surface, we also observed sites with water tables close to the surface being strongly dissimilar to their nearnatural counterparts. The general patterns indicate that restoration success depends on more than just a water table close to the surface (Supplementary Fig. 2).

Locally novel ecosystems require functional understanding. With the existing dataset we cannot answer why some rewetted sites resemble near-natural counterparts right away, while others follow diverging trajectories for decades, indicating that the natural fens can become novel ecosystems sensu Hobbs et al. ${ }^{41}$, i.e., non-restorable at least for several decades, due to prolonged drainage (Fig. 4). Duration and intensity of drainage might likely matter here ${ }^{3}$ as these determine nutrient availability and irreversible changes in peat hydraulic variables (Fig. 4b). Existing knowledge from natural systems about ecological functions, external regulation, self-regulation, and ecosystem service provision appears hardly transferable for understanding and managing these locally novel ecosystems. Therefore, we call for a concerted action to assemble data about ecological functions and relevant meta information of rewetted peatlands as laid out by Bonnett et $\mathrm{al}^{42}$. Understanding causes and consequences of restoration success will likely require the assessment of peat microbiomes and 

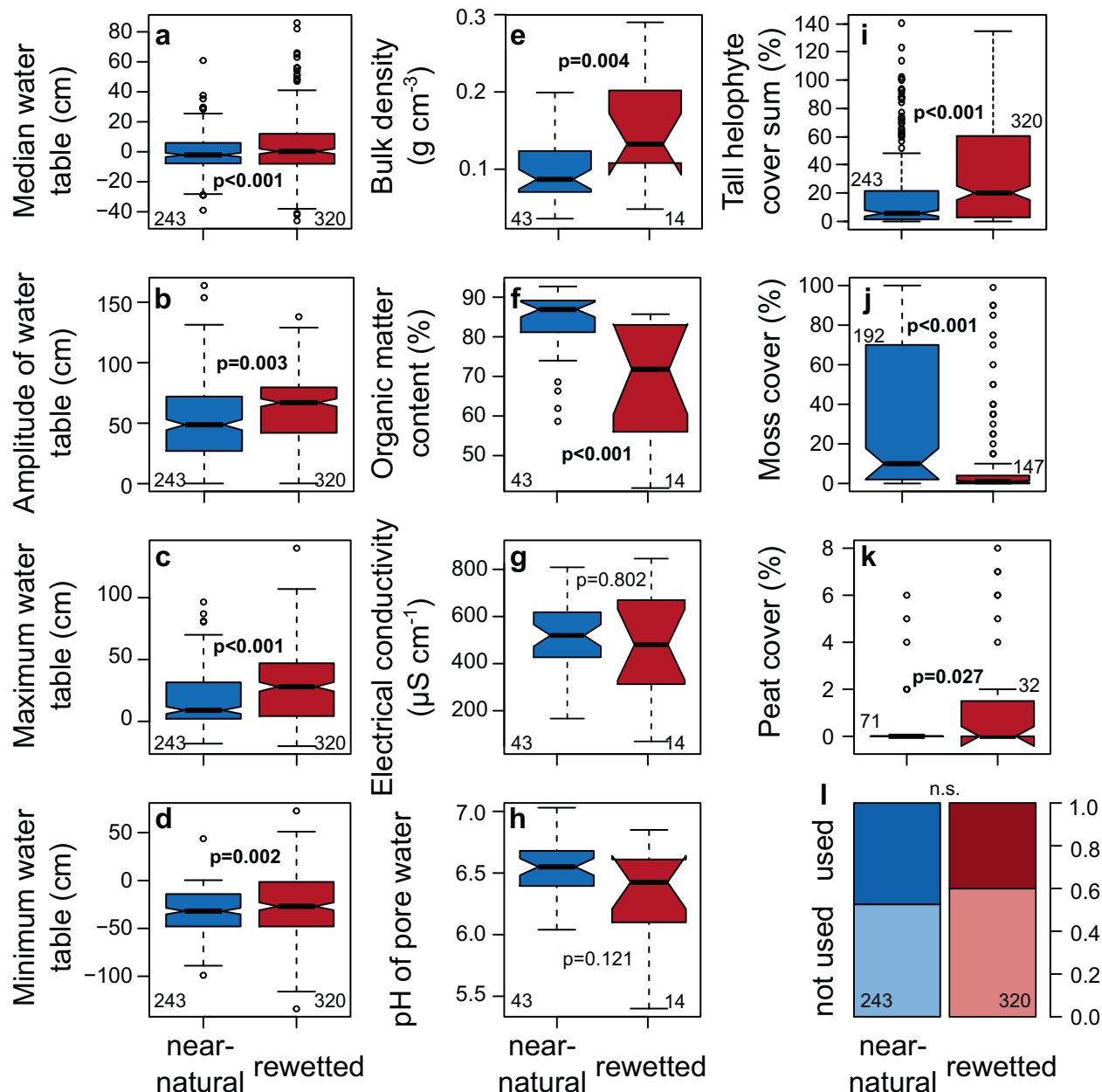

Fig. 3 Rewetted fen peatlands differ in relevant ecological parameters from near-natural fen peatlands. Comparison between rewetted (red) and nearnatural (blue) sites for all parameters used in the analyses for hydrology (a-d) and for geochemistry (e-h) alongside selected other relevant parameters (i-m). 'Tall helophyte cover sum' (i) is the sum over all tall helophyte species cover values according to Chytrý et al. ${ }^{28}$. Asterisks indicate significance of differences according to two-sided Wilcoxon-rank test for numerical and $\mathrm{Chi}^{2}$ test for factorial response parameters $\left({ }^{\star \star \star} p<0.001 ;{ }^{* \star} p<0.01 ;{ }^{\star} p<0.05\right)$. $n$ per group is provided as numbers next to the boxplots, $n$ differs between parameters as data was not available for all sites and all parameters, respectively. The boxplots display the median, quartiles (box), 1.5-fold quartile distance (whiskers) and extremes beyond the whiskers.

key microbial players in organic matter mineralization and GHG production and consumption and the GHG fluxes alongside vegetation, hydrology, pore water chemistry as well as chemical and physical peat properties.

Recently published studies showing that rewetted peatlands can act as carbon sinks even during extended dry and hot periods ${ }^{43,44}$ are encouraging, although the stop of continued carbon losses from peat degradation is the most pressing issue today ${ }^{14}$. However, historical drainage of peatlands followed by rewetting creates locally novel ecosystems in many cases. Understanding and management schemes cannot be transferred from natural systems. Instead, an interdisciplinary, process-based understanding of the rewetted systems is urgently needed to prioritize, plan and implement restoration measures and to design their sustainable management. The UN Decade of Ecosystem Restoration starting just now is the critical period for achieving our commitments of the Paris Agreement on peat soils ${ }^{2}$ and for peatland science.

\section{Methods}

Site selection. A total of 320 rewetted sites was compared to 243 undrained, nearnatural sites (Supplementary Data 1), covering the major distribution range of temperate fens across Europe (Fig. 1). We included all sites where local experts confirmed a dateable rewetting action, usually the blocking of drainage systems, which led to a mean annual water table of $25 \mathrm{~cm}$ below surface or higher. Rewetting occurred on average 9 years (min. 1 and max. 54 years) before data sampling. Land use before rewetting was agriculture ( $80 \%$ of all rewetted sites), forestry $(10 \%)$ or peat extraction (10\%). We acknowledge that few, if any, untouched and completely natural temperate fens exist nowadays in Europe. For our comparison, we used sites without direct drainage history, again relying on local expert knowledge. We confirmed this by carefully checking field conditions and aerial/satellite imagery for structures which would imply substantial former drainage and disregarded those with such features. Our study contains some of the least disturbed fens in temperate Europe (Eastern Poland and Belarus).

Response parameters. We included sites that provided data for at least two of the following four response clusters:

(1) Vegetation: complete lists of vascular plants and bryophytes (539 species in total) based on $16 \mathrm{~m}^{2}$ (median, ranging between 12 and $25 \mathrm{~m}^{2}$ ) with estimates of individual plant species cover. All vegetation data collections included in this study aimed at full species lists and used comparable methodologies, i.e., estimating species-specific cover values. Studies focusing on specific taxa or just reporting the dominant species were excluded from the analyses. Mean species richness per plot was 15.1 (ranging from 2 to 63).

(2) Hydrology: 269 piezometers with dataloggers, 91 piezometers related to a datalogger in a transect, 216 piezometers with manual measurements of at least one year and biweekly or monthly readings of the water table depth relative to the peat surface. The vast majority $(>80 \%)$ of these datasets with only biweekly or monthly measurements were carried out for $>2$ years, so that we are confident in their power to estimate the temporal dynamics at the respective sites representatively. On average, 2.3 years were measured, 

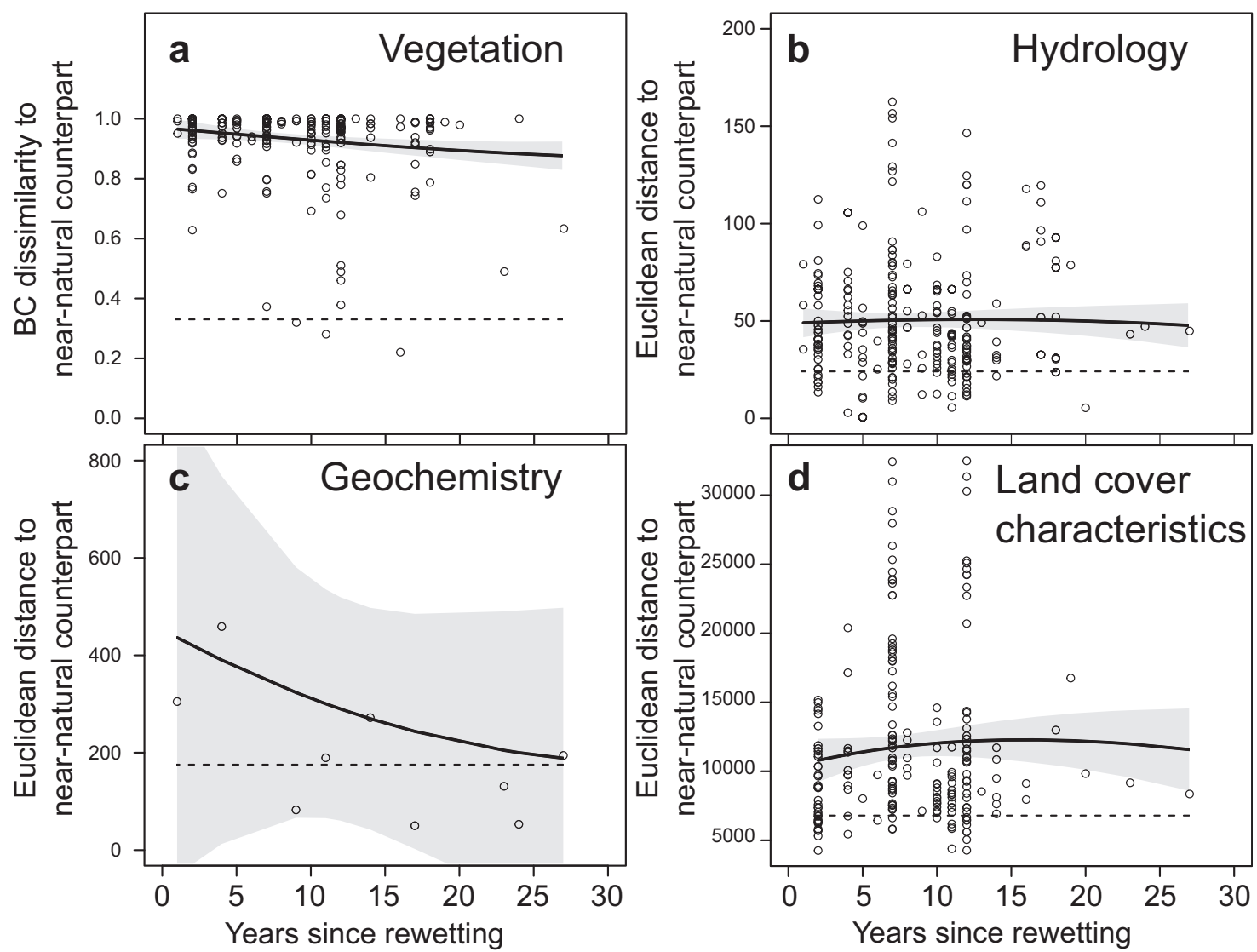

Fig. 4 Strong differences and little to no temporal trend in the pairwise dissimilarity between rewetted sites and near-natural counterparts of similar origin. Dissimilarity in unitless Bray-Curtis (BC) dissimilarity for the vegetation ( $0=$ identical species composition, $1=$ no shared species) and in Euclidean distance ( 0 to infinite) for the other response clusters between each rewetted site with a near-natural counterpart (same peatland origination, comparable altitude, same biogeographic zone, minimum spatial distance) against the time since restoration. Black lines indicate a LOESS spline with span $=1.4$ (lowest span not leading to uninformative multiple local minima or maxima) and its $95 \%$ confidence interval shaded in gray. Horizontal dashed lines indicate the mean dissimilarity between pairs of near-natural sites selected the same way as the near-natural counterparts of the rewetted sites. Linear models indicate highly significant intercepts ( $p<0.001$ for all four response clusters) and no significant slopes $(p>0.6)$ except for vegetation $(p=0.013)$.

and we included only data if available for at least one full year. All water table measurements have been made in direct vicinity to the vegetation relevée. We considered the annual median water table, annual minimum water table, annual maximum water table, and annual amplitude of water table (max minus min) as relevant response parameters. Data for water tables during the growing season were highly correlated to the annual water table data (annual median versus median throughout summer and autumn: $r^{2}=0.89$; annual median versus median throughout winter and spring: $r^{2}=0.94$; annual maximum versus maximum throughout summer and autumn: $r^{2}=0.85$; annual maximum versus maximum throughout winter and spring: $r^{2}=0.86$; annual minimum versus minimum throughout summer and autumn: $r^{2}=0.91$; annual minimum versus minimum throughout winter and spring: $r^{2}=0.73$ ).

(3) Geochemistry: $\mathrm{pH}$ and electrical conductivity of the pore water $(0-60 \mathrm{~cm})$, bulk density and organic matter content of the top soil layer $(0-30 \mathrm{~cm})$ sampled in summer for all sites included here alongside the vegetation data sampling. The parameters considered for geochemistry and also for hydrology had to be chosen in order to maximize data availability in parallel with meaningfulness. Note that, still, geochemical data are only available for a subset of the full data set 57 sites; see Fig. 3e-h for sample size per group). Despite the low sample size, it is important to note that the remaining sites cover almost the whole geographical range of the other response parameters (Eastern Poland, Eastern and Northern Germany, the Netherlands, Belgium, Wales) and no geographical or ecological bias was found. In addition, the remaining sites contain well-comparable pairs of rewetted and near-natural sites throughout this geographical space. While the selected parameters allow for relevant insights, more specific response parameters are required for process-based understanding of the biogeochemistry of rewetted peatlands ${ }^{42}$.

(4) Land cover characteristics: spectral-temporal metrics for a full annual time series of Copernicus Sentinel-2 A/B data for 2018. The Sentinel-2 A/B constellation provides optical imagery of the Earth's surface between $\sim 0.49-\sim 2.2 \mu \mathrm{m}$ in ten spectral bands and at $10-20 \mathrm{~m}$ ground sampling distance at a theoretical acquisition frequency of 2.5-5 days. We here acquired all available Sentinel-2 A/B imagery for 2018 with cloud cover $<70 \%$ from the ESA API Hub. We used all valid observations to derive spectral-temporal metrics from the time series. Spectral temporal metrics are statistical measures (e.g., average, minimum, maximum, quartiles, ...) per spectral band or index (e.g., $M N D W I=$ (green - short wave infrared) (green + short wave infrared ${ }^{45}$ ) using all available cloud- and shadow-free observations over time. The median count of clear-sky-observations per pixel across the sites is 45 , while $90 \%$ of all sites featured 27 clear-sky observations or more. Both data processing to Analysis Ready Data as well as calculating spectral-temporal metrics was performed through the Framework for Operational Radiometric Correction for Environmental monitoring ${ }^{35}$. Our analysis included data averaged over $3 \times 3$ pixels around the center plot location of the site. Different spatial aggregations (e.g., single pixels, $5 \times 5$ pixels around the center plot) led to highly similar results, implying that the intra-site variability was robust around locations of the vegetation survey. The inclusion of an annual series of Sentinel-1 synthetic aperture radar data (temporal metrics for $\mathrm{VV}$ and $\mathrm{VH}$ polarization, IW swath at $10 \mathrm{~m}$ resolution) for the same year did not affect the results.

The representativeness of our database is confirmed by the comparison to $10 \mathrm{k}$ vegetation plots from all over Europe. These have been randomly chosen from $>90 \mathrm{k}$ vegetation plots of the European Vegetation Archive ${ }^{46}$, classified as belonging to peatland types (Q2: "Poor fens", Q4: "Calcareous rich fens", Q5: "Tall helophyte beds", Qa: "Mires") of the EUNIS habitat types ${ }^{18,28}$. Plant taxa have been standardized to Euro + Med plantbase ${ }^{47}$ and the checklist of bryophytes of Europe ${ }^{48}$ and harmonized to exclude nested taxa (option maxtaxtable = 'AG1' and $\mathrm{ag}=$ 'conflict' in function taxval in $\mathrm{R}$ package vegdata $\left.{ }^{49}\right)$.

Statistical analyses. An ordination (non-metrical multidimensional scaling, Bray-Curtis distance and step-across dissimilarities for those plot distances without common species with function 'metaMDS' from R-package 'vegan' 2.5-6) was 
applied in parallel to an analysis of similarity (function 'anosim' from package 'vegan' 2.5-6.) to test for significance of differences among rewetted and nearnatural peatlands. An Indicator Species Analysis ${ }^{50}$ (function 'indval' from package 'labdsv' version 2.0-1) was applied to find plant species with significant affinity to rewetted or near-natural peatlands. NMDS ordinations and analyses of similarity based on Euclidean distance were calculated for the other three response clusters, i.e., hydrology, geochemistry, and land cover characteristics. Variance, quantified as pairwise distance in the response clusters, was compared between rewetted and near-natural sites by testing for significance of differences in mean values per group. As data points in pairwise dissimilarity matrices are not strictly independent $t^{51}$ and homoscedasticity and normal distribution of residuals were questionable, we relied on permutation based procedures for estimating the significance of differences in mean values of pairwise dissimilarities between groups ${ }^{51}$ (function 'diffmean' from package 'simba' version 0.3-5 with 1000 permutations per test).

In order to account for large variance in the predictors due to the broad spatial coverage of our database, additional analyses relied on pairwise comparisons between rewetted sites and near-natural counterparts. All sites were classified according to their biogeographic peatland region and hydrogenetic and ecological fen type according to Joosten et al. ${ }^{10}$. Then, the spatially closest nearnatural counterpart was assigned to each rewetted site (Supplementary Data 1). If no counterpart within the class was available, the site was disregarded for the pairwise analysis. For sites from mountainous regions, mainly southern Germany, counterparts also had to stem from similar altitudes and sites with no near-natural counterpart within the same class and at similar altitude were disregarded. For comparison, near-natural-to-near-natural pairs were built using the same methodology and mean near-natural-to-near-natural dissimilarity is displayed in Fig. 4 as horizontal dashed line. Mean distance between rewettedto-natural counterparts were $9,40,11$, and $21 \mathrm{~km}$ for vegetation, hydrology, geochemistry and land cover characteristics, respectively, whereas near-naturalto-near-natural pairs were $8,20,21$, and $11 \mathrm{~km}$ apart from each other on average.

Reporting summary. Further information on research design is available in the Nature Research Reporting Summary linked to this article.

\section{Data availability}

The data generated and analyzed in this study have been deposited in the Dryad database under https://doi.org/10.5061/dryad.08kprr532. The plot-based vegetation data used for comparison to this dataset is available at the European Vegetation Archive ${ }^{46}$.

\section{Code availability}

All analyses were carried out with the functions and additional packages specified in the methods section in the free and open-source environment $\mathrm{R}^{52}$.

Received: 4 May 2021; Accepted: 13 August 2021;

Published online: 05 October 2021

\section{References}

1. Schoock, M. Tractatus de turffis ceu cespitibus bituminosis: quo multa, ab aliis hactenus aut neglecta, aut minus diligenter examinata, accuratius aliquanto excutiuntur. [A treatise on peats as bituminous sods] (Cöllen, Groningen, 1658).

2. Tanneberger, F. et al. Towards net zero CO2 in 2050: An emission reduction pathway for organic soils in Germany. Mires Peat 27, 1-17, https://doi.org/ 10.19189/MaP.2020.SNPG.StA.1951 (2021).

3. Klimkowska, A. et al. Are we restoring functional fens? - The outcomes of restoration projects in fens re-analysed with plant functional traits. PLOS One 14, e0215645, https://doi.org/10.1371/journal.pone.0215645 (2019).

4. Emsens, W.-J. et al. Recovery of fen peatland microbiomes and predicted functional profiles after rewetting. ISME J. 14, 1701-1712, https://doi.org/ 10.1038/s41396-020-0639-x (2020).

5. Lamers, L. P. M. et al. Ecological restoration of rich fens in Europe and North America: from trial and error to an evidence-based approach. Biol. Rev. 90, 182-203, https://doi.org/10.1111/brv.12102 (2015).

6. Findorff, J. C. Beiträge und Fragmente zu einem Moorkatechismus/von Jürgen Christian Findorff und Anmerkungen von F. Brüne, K. Lilienthal und F. Overbeck. [Contributions and fragments to a peatland catechism from Jürgen Christian Findorff with remarks from F. Brüne, K. Lilienthal and F. Overbeck] (Stalling, Oldenburg, 1764, published 1937).

7. Kirpotin, S. N. et al. Great Vasyugan Mire: How the world's largest peatland helps addressing the world's largest problems. Ambio 71, 618, https://doi.org/ 10.1007/s13280-021-01520-2 (2021).
8. Scharlemann, J. P. W., Tanner, E. V. J., Hiederer, R. \& Kapos, V. Global soil carbon: understanding and managing the largest terrestrial carbon pool. Carbon Manag. 5, 81-91, https://doi.org/10.4155/cmt.13.77 (2014).

9. Xu, J., Morris, P. J., Liu, J. \& Holden, J. Hotspots of peatland-derived potable water use identified by global analysis. Nat. Sustain. 1, 246-253, https:// doi.org/10.1038/s41893-018-0064-6 (2018).

10. Joosten, H., Tanneberger, F. \& Moen, A. (eds). Mires and peatlands of Europe. Status, distribution and conservation (Schweizerbart Science Publishers, Stuttgart, 2017).

11. Bonn, A., Allott, T., Evans, M., Joosten, H. \& Stoneman, R. (eds). Peatland restoration and ecosystem services (Cambridge University Press, Cambridge, 2016).

12. Leifeld, J. \& Menichetti, L. The underappreciated potential of peatlands in global climate change mitigation strategies. Nat. Commun. 9, 1071, https:// doi.org/10.1038/s41467-018-03406-6 (2018).

13. Joosten, H. \& Clarke, D. Wise use of mires and peatlands. Background and principles including a framework for decision-making (Internat. Mire Conservation Group, Totnes, 2002).

14. Günther, A. et al. Prompt rewetting of drained peatlands reduces climate warming despite methane emissions. Nat. Commun. 11, 1644, https://doi.org/ 10.1038/s41467-020-15499-z (2020).

15. Erkens, G., van der Meulen, M. J. \& Middelkoop, H. Double trouble: subsidence and $\mathrm{CO}_{2}$ respiration due to 1,000 years of Dutch coastal peatlands cultivation. Hydrogeol. J. 24, 551-568, https://doi.org/10.1007/s10040-0161380-4 (2016).

16. Tiemeyer, B. \& Kahle, P. Nitrogen and dissolved organic carbon (DOC) losses from an artificially drained grassland on organic soils. Biogeosciences 11, 4123-4137, https://doi.org/10.5194/bg-11-4123-2014 (2014).

17. Minayeva, T., Bragg, O. \& Sirin, A. Peatland biodiversity and its restoration. In Peatland restoration and ecosystem services, (eds Bonn, A., Allott, T., Evans, M., Joosten, H. \& Stoneman, R.) pp. 44-62 (Cambridge University Press, Cambridge, 2016).

18. Janssen, J. A. M. et al. European red list of habitats (Publications Office of the European Union, 2016).

19. Mrotzek, A., Michaelis, D., Günther, A., Wrage-Mönnig, N. \& Couwenberg, J. Mass balances of a drained and a rewetted peatland: on former losses and recent gains. Soil Syst. 4, 16, https://doi.org/10.3390/soilsystems4010016 (2020).

20. Zerbe, S. et al. Ecosystem service restoration after 10 years of rewetting peatlands in NE Germany. Environ. Manag. 51, 1194-1209, https://doi.org/ 10.1007/s00267-013-0048-2 (2013).

21. Leifeld, J., Wüst-Galley, C. \& Page, S. Intact and managed peatland soils as a source and sink of GHGs from 1850 to 2100. Nat. Clim. Change 9, 945-947, https://doi.org/10.1038/s41558-019-0615-5 (2019).

22. IPCC. Global warming of $1.5^{\circ} \mathrm{C}$ (IPCC, Geneva, Switzerland, 2018).

23. Liu, H. \& Lennartz, B. Hydraulic properties of peat soils along a bulk density gradient-A meta study. Hydrol. Process 33, 101-114, https://doi.org/10.1002/ hyp.13314 (2019).

24. Franz, D., Koebsch, F., Larmanou, E., Augustin, J. \& Sachs, T. High net $\mathrm{CO}_{2}$ and $\mathrm{CH}_{4}$ release at a eutrophic shallow lake on a formerly drained fen. Biogeosciences 13, 3051-3070, https://doi.org/10.5194/bg-13-3051-2016 (2016).

25. Hemes, K. S., Chamberlain, S. D., Eichelmann, E., Knox, S. H. \& Baldocchi, D. D. A biogeochemical compromise: the high methane cost of sequestering carbon in restored wetlands. Geophys. Res. Lett. 45, 6081-6091, https:// doi.org/10.1029/2018GL077747 (2018).

26. Zak, D. \& Gelbrecht, J. The mobilisation of phosphorus, organic carbon and ammonium in the initial stage of fen rewetting (a case study from NE Germany). Biogeochemistry 85, 141-151, https://doi.org/10.1007/s10533-0079122-2 (2007).

27. Emsens, W.-J., Aggenbach, C. J. S., Smolders, A. J. P., Zak, D. \& van Diggelen, R. Restoration of endangered fen communities: the ambiguity of ironphosphorus binding and phosphorus limitation. J. Appl. Ecol. 54, 1755-1764, https://doi.org/10.1111/1365-2664.12915 (2017).

28. Chytrý, M. et al. EUNIS Habitat Classification: Expert system, characteristic species combinations and distribution maps of European habitats. Appl. Veg. Sci. 23, 648-675, https://doi.org/10.1111/avsc.12519 (2020).

29. Zak, D. et al. Unraveling the importance of polyphenols for microbial carbon mineralization in rewetted riparian peatlands. Front. Environ. Sci. 7; https:// doi.org/10.3389/fenvs.2019.00147 (2019).

30. Henneberg, A., Sorrell, B. K. \& Brix, H. Internal methane transport through Juncus effusus: experimental manipulation of morphological barriers to test above- and below-ground diffusion limitation. N. Phytol. 196, 799-806, https://doi.org/10.1111/j.1469-8137.2012.04303.x (2012).

31. Agethen, S., Sander, M., Waldemer, C. \& Knorr, K.-H. Plant rhizosphere oxidation reduces methane production and emission in rewetted peatlands. Soil Biol. Biochem 125, 125-135, https://doi.org/10.1016/j.soilbio.2018.07.006 (2018). 
32. Vitt, D. H. Peatlands: ecosystems dominated by bryophytes. In Bryophyte biology, (eds Shaw, A. J. \& Goffinet, B.), pp. 312-343 (Cambridge University Press, Cambridge, 2002).

33. Wilson, D. et al. Greenhouse gas emission factors associated with rewetting of organic soils. Mires Peat, 1-28; https://doi.org/10.19189/MaP.2016.OMB.222 (2016).

34. Kotowski, W., Thörig, W., van Diggelen, R. \& Wassen, M. J. Competition as a factor structuring species zonation in riparian fens - a transplantation experiment. Appl. Veg. Sci. 9, 231-240, https://doi.org/10.1111/j.1654109X.2006.tb00672.x (2006).

35. Frantz, D. FORCE-Landsat+ Sentinel-2 Analysis Ready Data and Beyond Remote Sens. 11, 1124, https://doi.org/10.3390/rs11091124 (2019).

36. Körner, C., Stöcklin, J., Reuther-Thiébaud, L. \& Pelaez-Riedl, S. Small differences in arrival time influence composition and productivity of plant communities. N. Phytol. 177, 698-705, https://doi.org/10.1111/j.14698137.2007.02287.x (2008).

37. Fritz, C., Campbell, D. I. \& Schipper, L. A. Oscillating peat surface levels in a restiad peatland, New Zealand-magnitude and spatiotemporal variability. Hydrological Process. 22, 3264-3274, https://doi.org/10.1002/hyp.6912 (2008).

38. Loisel, J. \& Yu, Z. Surface vegetation patterning controls carbon accumulation in peatlands. Geophys. Res. Lett. 40, 5508-5513, https://doi.org/10.1002/ grl.50744 (2013).

39. Koebsch, F. et al. The impact of occasional drought periods on vegetation spread and greenhouse gas exchange in rewetted fens. Proc. R. Soc. Lond. B Biol. Sci. 375, 20190685, https://doi.org/10.1098/rstb.2019.0685 (2020).

40. Fenner, N. \& Freeman, C. Drought-induced carbon loss in peatlands. Nat. Geosci. 4, 895-900, https://doi.org/10.1038/ngeo1323 (2011).

41. Hobbs, R. J., Higgs, E. S. \& Hall, C. M. Defining novel ecosystems. In Novel Ecosystems. Intervening in the New Ecological World Order (eds Hobbs, R. J., Higgs, E. S. \& Hall, C.) 1st ed., Vol. 24, pp. 58-60 (Wiley-Blackwell, s.l., 2013).

42. Bonnett, S. A. F., Ross, S., Linstead, C. \& Maltby, E. A review of techniques for monitoring the success of peatland restoration. Natural England Commissioned Reports, Number 086 and Natural England Technical Information Note TIN097. http://publications.naturalengland.org.uk/ publication/46013 (2011)

43. Schwieger, S. et al. Wetter is better: Rewetting of minerotrophic peatlands increases plant production and moves them towards carbon sinks in a dry year. Ecosystems 45, 279, https://doi.org/10.1007/s10021-020-00570-z (2020).

44. Beyer, F. et al. Drought years in peatland rewetting: rapid vegetation succession can maintain the net $\mathrm{CO}_{2}$ sink function. Biogeosciences 18, 917-935, https://doi.org/10.5194/bg-18-917-2021 (2021).

45. Xu, H. Modification of normalised difference water index (NDWI) to enhance open water features in remotely sensed imagery. Int. J. Remote Sens. 27, 3025-3033, https://doi.org/10.1080/01431160600589179 (2006).

46. Chytrý, M. et al. European Vegetation Archive (EVA): an integrated database of European vegetation plots. Appl. Veg. Sci. 19, 173-180, https://doi.org/ 10.1111/avsc.12191 (2016).

47. Euro+Med 2006+. Euro+Med PlantBase - the information resource for Euro-Mediterranean plant diversity. https://www.europlusmed.org. Accessed 25-Feb-2021.

48. Hodgetts, N. G. et al. An annotated checklist of bryophytes of Europe, Macaronesia and Cyprus. J. Bryol. 42, 1-116, https://doi.org/10.1080/ 03736687.2019.1694329 (2020).

49. Jansen, F. \& Dengler, J. Plant names in vegetation databases - a neglected source of bias. J. Veg. Sci. 21, 1179-1186, https://doi.org/10.1111/j.16541103.2010.01209.x (2010).

50. Dufrene, M. \& Legendre, P. Species assemblages and indicator species: the need for a flexible asymmetrical approach. Ecol. Monogr. 67, 345-366 (1997).

51. Jurasinski, G. \& Kreyling, J. Upward shift of alpine plants increases floristic similarity of mountain summits. J. Veg. Sci. 18, 711-718 (2007).

52. R Core Team. $R$ : a language and environment for statistical computing. $R$ version 4.0.2 (R Foundation for Statistical Computing. URL http://www.Rproject.org, Vienna, Austria, 2020).
53. Tanneberger, F. et al. The peatland map of Europe. Mires Peat, 1-17; https:// doi.org/10.19189/MaP.2016.OMB.264 (2017).

\section{Acknowledgements}

This research was funded by the European Social Fund (ESF) and the Ministry of Education, Science and Culture of Mecklenburg-Western Pomerania within the scope of the project WETSCAPES (ESF/14-BM-A55-0027/16 to ESF/14-BM-A55-0035/16) and by DFG JO 332/15-1, BELSPO BR/175/A1, NCN 2016/22/Z/NZ8/00001 within the scope of the BiodivERsA project REPEAT within the Horizon 2020 ERA-NET COFUND scheme and by FWO 1214520N. We thank Carl Barnick, Heinrich Belting, Kathrin Brozio, Ulrich Fischer, Beate Geiger-Udod, Johanna Heck, Janusz Kloskowski, Eva Rosinski, Ute Schmidt and Robert Stanko for providing data.

\section{Author contributions}

F.Ta., G.J., J.K. designed this study. A.K., B.L., C.A., E.S., E.V., G.J., F.J., F.Ta., H.J., J.C., J.K., L.K., M.W., N.W.M., R.v.D., T.U., W.-J.E., W.K. conceived the research question. A.K., A.S., A.P., B.T., C.A., C.O., C.S., D.Z., E.P., E.S., F.J., F.Ta., H.L., J.S., K.P., K.R., K.V., L.K., L.W., M.R., R.v.D., S.R., S.T., T.T., V.B., W.-J.E., W.K., Y.L. contributed data F.Ta. assembled and harmonized the data. F.Ta. and D.M. checked all data and assigned the pairwise counterparts. F.J. harmonized the vegetation data with the additional vegetation plot data, added the EUNIS classification and ran the ordination for the vegetation data. S.v.L., F.S., F.Th. contributed the land cover characteristics data. J.K analyzed the data and led the writing with all co-authors contributing.

\section{Funding}

Open Access funding enabled and organized by Projekt DEAL.

\section{Competing interests}

The authors declare no competing interests.

\section{Additional information}

Supplementary information The online version contains supplementary material available at https://doi.org/10.1038/s41467-021-25619-y.

Correspondence and requests for materials should be addressed to J. Kreyling.

Peer review information Nature Communications thanks Rebekka Artz and the other, anonymous, reviewer(s) for their contribution to the peer review of this work.

Reprints and permission information is available at http://www.nature.com/reprints

Publisher's note Springer Nature remains neutral with regard to jurisdictional claims in published maps and institutional affiliations.

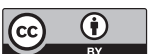

Open Access This article is licensed under a Creative Commons Attribution 4.0 International License, which permits use, sharing, adaptation, distribution and reproduction in any medium or format, as long as you give appropriate credit to the original author(s) and the source, provide a link to the Creative Commons license, and indicate if changes were made. The images or other third party material in this article are included in the article's Creative Commons license, unless indicated otherwise in a credit line to the material. If material is not included in the article's Creative Commons license and your intended use is not permitted by statutory regulation or exceeds the permitted use, you will need to obtain permission directly from the copyright holder. To view a copy of this license, visit http://creativecommons.org/ licenses/by/4.0/.

(C) The Author(s) 2021 